\title{
Continuing Education: A Vital Ingredient Of The ‘Success Plan' For Small Business
}

Rubik Atamian, University of Texas Pan American, USA

Neal R. VanZante, University of Texas Pan American, USA

\begin{abstract}
ABSTACT
In a recent Journal of Business \& Economics Research article, Atamian, et. al. (2009) provided practical advice for individuals considering forming a small business. In that article, the authors observed that a major factor in avoiding failure is to "plan for success." The authors further noted that operating even the smallest of businesses calls for a multiplicity of skills seldom found in one individual. This article discusses the knowledge and skills that the small business owner must have in order to combat risk of failure. Furthermore, it encourages small business owners to recognize the necessity of including a viable continuing education element in their plans for success. It concludes with an expanded discussion of how small business owners can continually acquire knowledge and skills to sustain the vitality of their businesses.
\end{abstract}

Keywords: Small Business Administration (SBA), SCORE, Small Business Development Centers, Small Business Institute, education for small business owners, continuing education, success plan

\section{INTRODUCTION}

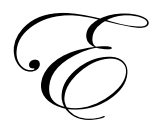

mpirical studies have identified several key reasons for the high rate of small business failure in the United States. In a recent article in the Journal of Business \& Economics Research, Atamian, et. al. (2009) provided practical advice for entrepreneurs starting a small business. The authors observed that an essential factor in preventing business failure is "planning for success." The authors further noted that successful operation of even the smallest of businesses calls for a multiplicity of skills seldom found in one individual.

Small business owners' lack of knowledge about important ingredients of operating a business is a recipe for failure. Many small business owners work in the business rather than on the business, and proceed by trial and error instead of following a proven successful strategy. A small business owner's product should be the business itself instead of what the business produces. However, this realization escapes the owners of many failing small businesses (Atamian, et. al. 2009). While acquisition of the required knowledge is not a guarantee for business success, it certainly is a necessary condition for achieving success. Small business owners must be knowledgeable about a wide range of business activities to ensure that they are performed proficiently and to make appropriate decisions about how and by whom these activities are to be performed.

To be successful, small business owners must command the generation and proper processing of vital operating data relevant to the functioning of the business. Additionally, they must be willing to accept responsibility for making continuing education in these areas a priority in the entity's strategic "plan for success." Small business owners must also be cognizant of the resources available to them in order to facilitate their procurement of required knowledge base in an efficient and cost-effective manner.

Schaefer (2006) notes that one cause of small business failure is lack of planning, while Isodoro (2008) includes "planning for success" as a rule for small business prosperity. The objectives of this paper are to discuss the knowledge and skills that small business owners must possess in order to prevail, to help them realize the necessity of including a viable continuing education element in their "plan for success," and to discuss how small business owners can acquire the knowledge and skills they need in order to provide ongoing support for effective management of their businesses. 


\section{KNOWLEDGE AND SKILLS NEEDED BY SMALL BUSINESS OWNERS}

The various skills that an entrepreneur must possess in order to successfully lead an independent business through its introduction and growth phases to maturity and profitability, calls for the consideration of activities vital to the flourishing operation of a small business. These activities can generally be divided into line and support (staff) activities. Line activities are those that the business was established to carry out and produce revenues. Because business owners are generally aware of the importance of their operating (line) activities and because, by necessity, they maintain their proficiency in these activities through additional training and education, little more needs to be said about the substance of these activities.

For a small business owner to be successful, he/she also needs to be proficient in handling the support (staff) functions. Although these activities do not directly generate revenues for the business, they are essential for its ongoing successful operation. These support activities include, but are not limited to, personnel matters, business policies and procedures, cash management, promotion and advertising, regulatory compliance, quality, and customer management.

Personnel matters encompass position advertisements, preparation of employment applications, interviewing, qualifying, hiring, training, motivating while promoting high ethical and moral demeanor, performance evaluation, and decisions to discipline and terminate. Additional personnel related activities include payroll processing and proper accounting and reporting of payroll taxes withheld. Effective and workable personnel policies and procedures are also vitally important to effective and consistent management of line functions that dictate the success or failure of a business enterprise.

Proficient cash management is imperative in assuring that the business meets its financial obligations and sustains its credit worthiness. As part of effective cash management, the small business owner must assure that a reliable system of internal controls is implemented to validate that general cash flows are fully accounted for, payments are made to legitimate creditors, and that its assets are protected. Regarding marketing and advertisement, the small business owner must be able to distinguish between effective venues and inconsequential means of promotion. Promotional creativity is vital to maintaining business momentum and sustainable profitability. Essential ingredients of a successful business plan addressing quality and customer management include job scheduling, quality control, timely completion of work, obtaining feedback from customers, and maintaining customer satisfaction.

Federal and State regulations are complex and ever changing. Depending on its industry, a small business would be required to periodically complete a varying number of regulatory compliance forms and reports in order to avoid penalties and interest and retain the right to conduct business. Monthly sales tax reports, quarterly and annual payroll tax reports, and property tax reports are common to virtually all small businesses. Additionally, a small business may need to comply with job safety and health regulations, equal employment opportunity (EEO) practices, fair labor practices, disabled employee rights, family and medical leave, and veterans' rights.

The forgoing is not intended to be an exhaustive discussion of all vital support activities. Nevertheless, it provides reasonable insight to the complex nature of a contemporary small business and its operations. A business owner who pays attention to all facets of managing a business will have a better chance of succeeding than one who does not. However, there is a limit to the amount of effort that a small business owner can devote to functions that sustain the business rather than those that produce revenues. While a large company is able to devote a sizable ratio of its personnel to support activities, a small company is not in a position to do so, although they are as vital to the success of the small business as are line functions. Nonetheless, the small business owner needs to gain the working knowledge needed to perform support activities himself, to outsource these activities to professionals, or to hire qualified personnel to handle them internally. Regardless, the small business owner must have enough knowledge about the support activities in order to make the correct decisions about how they will be carried out and by which specific personnel. 


\section{THE IMPORTANCE OF CONTINUING EDUCATION FOR THE SMALL BUSINESS OWNER}

The value of continuing education programs is well recognized by many professional groups including accountants and medical technicians. Numerous other professionals place a high priority on continuing education because they must remain current in contemporary developments in their fields to perform their job-related functions. As noted earlier, small business owners readily admit the importance of up-to-date skills and relevant education in fulfilling their "line" related duties.

The entrepreneur who recognizes that the ultimate product is the business itself also values the importance of continuing education for staff functions. Similarly, such businesspersons further recognize that they must devote personal time and effort to their participation in a variety of costly continuing education programs. The time and other resources they spend in maintaining their competence in handling support functions will pay off by preventing potential wasteful losses that could occur in various stages of production and sale. In other words, the successful small business owner fully understands that an ounce of prevention (education) is worth a pound of cure (correcting mishaps) that in this case would include the cost of undoing errors and remedying otherwise avoidable non-valueadded circumstances.

A viable continuing education program for small business owners should have the flexibility to provide the relevant knowledge they need as well as when and where they need it. Small business owners need the knowledge more than they need the credit for having mastered the knowledge. They need a supervised learning environment that helps them curb their anxieties about the subject, alleviates feeling of being overwhelmed, and facilitates an atmosphere that provides them the confidence to apply what they learn.

\section{SOURCES OF CONTINUING EDUCATION}

The extent of continuing education program opportunities available to small business owners depends on their geographic location. Naturally, businesses located in major metropolitan areas would have greater opportunities than those in remote areas. Similarly, businesses operating near a multitude of colleges and universities are likely to have access to a wider array of educational resources. Internet technology and online instruction, however, offer alternative learning opportunities comparable to those offered by traditional colleges and universities. Nevertheless, whether or not the small business owners fit the profile of proficient online learners remains doubtful. Although not an exhaustive list of continuing educational resources, following is a discussion of specialized learning opportunities for small business offered by several key governmental and non-governmental entities.

\section{Small Business Administration}

For the small business owner seeking assistance in gaining necessary knowledge on a range of subjects, a starting point could be the Small Business Administration (SBA). The United States SBA was created in 1953 as an independent agency of the federal government to aid, counsel, assist, and protect the interests of small business concerns, to preserve free competitive enterprise, and to maintain and strengthen the overall economy of the nation. The SBA helps American small businesses' long-term growth and prosperity. Through partnerships with public and private organizations and an extensive network of field offices, the SBA delivers its services throughout the United States, Puerto Rico, the U. S. Virgin Islands and Guam (SBA 2009).

The SBA's website provides a wealth of free information about a variety of subjects arranged under four major headings: Small Business Planner, Services, Tools, and Local Resources. The Services heading provides "counseling and assistance" links to SBA partners: SCORE, Small Business Development Centers, and Womens Business Centers. Additional links are provided under the Local Resources heading. Under the Services heading, small business owners gain access to many on-line courses covering a diverse group of topics. Each self-paced course is designed to be completed in about 30 minutes. Courses are clustered under several headings including starting a business, business management, finance and accounting, marketing and advertising, and others relevant subjects. Online courses available on the SBA's website are also available in Spanish. 
The tools available on the website include library as well as audio/video resources. The Tools category provides small business owners access to sizable educational materials in text, audio, and video formats. These materials include various topics of interest to small business owners including articles dealing with management and planning, financial management, marketing, personal management, and crime prevention. In sum, the SBA website provides small business owners relevant continuing education opportunities not readily available elsewhere. These resources are designed to be both cost-effective and time-efficient. Certainly, the SBA resources could be a vital starting point for those small business owners who wish to gain knowledge essential to successful business operations.

\section{Counselors to America's Small Business (SCORE)}

Originally founded as Service Corps of Retired Executives in 1964, SCORE is a nonprofit national association dedicated to the establishment, growth, and success of small business and educating entrepreneurs. Headquartered in Herndon, Virginia, SCORE has 370 Chapters throughout the country. There are over 11,000 working and retired business owners who volunteer for SCORE by donating their time and expertise to serve as volunteer counselors (SCORE 2009).

As an SBA resource partner, SCORE provides mentoring and training for entrepreneurs. SCORE offers free and confidential advice to small business owners through face-to-face and online counseling, as well as webbased workshops. The association's website presently offers 26 online workshops in three categories of "starting your own business," "foundations of marketing," and "managing your finances." Online services are available in both English and Spanish

\section{Small Business Development Centers}

Small Business Administration oversees the activities of the Small Business Development Center (SBDC) program that provides management assistance to current and prospective small business owners. SBDC disseminates timely and relevant information and guidance in centrally located branch offices. The program is a cooperative effort of the private sector, the educational community, and federal, state and local governments. There are currently 63 lead Centers with at least one located in each state, and a network of over 1,100 service locations strategically located within universities, community colleges, chambers of commerce, and economic development corporations (SBDC 2009).

SBDCs tailor their assistance to the needs of individual clients while considering the welfare of the local community. Each center develops services in cooperation with regional SBA district offices in order to minimize overlaps with other resource providers across the state. While SBDCs provide a range of services to small business owners, the focus of this article is the educational programs offered to small business owners.

Joyce Rosenberg (2008) sites the Georgia Small Business Development Center network that offers courses in several cities primarily for nominal fees. She notes that courses offered by various centers may, however, vary in content and type. Nonetheless, most offer instruction on basics of business finance, business management, and using accounting software.

\section{Internal Revenue Service Small Business Center}

The Internal Revenue Service (IRS) Small Business and Self-Employed Tax Center offers online learning and various other educational opportunities. While these educational resources are primarily related to tax reporting issues, some transcripts, videos, and workshops deal with various other topics relevant to small business owners, including disaster planning, identity theft, and Ponzi schemes.

\section{Trade Shows}

Virtually every industry has its regional, national, and international trade shows normally held in geographic areas with notable family and entertainment attractions. These shows, more often than not, incorporate 
seminars, workshops, and competitions in their programs that cover topics ranging from introduction to contemporary techniques in the field to insurance, employment and tax issues, and relevant proposed legislation. Although the experience of attending major trade shows may be costly, they can often be justifiable and, at times, rewarding.

\section{Trade Associations}

Small businesses are encouraged to join an existing trade association in their area or form one if none exists. Such associations are able to solicit qualified instructors from local colleges, insurance companies, public accounting firms, banks, and other similar institutions, to attend their periodic meetings to discuss specific topics of interest to the members. The experts may agree to lecture on a pro bono basis or, alternatively, be fully or partially sponsored by the area Chamber or a local business. The workshop and seminar costs can also be supplemented by participating association members.

\section{Local Chambers of Commerce}

Membership in the local chamber of commerce can be decidedly fruitful. Through brochures, newsletters, and periodic gatherings, chambers keep their membership informed of significant developments in the region that could affect the local economy and specific industries. Additionally, the chamber could help individual businesses in many ways, including organizing educational forums by serving as a liaison between the business community and the regional educational institutions.

\section{Degree Programs}

Institutions of higher education of all types offer established degree programs in small business management. Despite being meritorious, such degree programs are out of the reach of many small businesses, and are mostly irrelevant to the ad hoc needs of many small business owners. The quality and cost of these educational programs vary widely depending on whether the provider is a not-for-profit university or a profit seeking educational institution. As such, small business owners need to prudently evaluate the costs and benefits of a small business management degree similar to those of any other major business investment.

\section{Other Sources of Continuing Education}

In addition to the above mostly not-for-profit educational resources, there are many management consulting firms, financial institutions, insurance companies, investment houses, and financial advisors who provide mini educational conferences for sizable registration fees. Needless to say, business owners need to exercise due diligence when evaluating free or inexpensive educational offers from entities with a profit motive.

\section{SUMMARY AND CONCLUDING REMARKS}

This article discusses some of the knowledge and skills that the small business owner must possess in order to be successful. Because small business owners are likely to maintain currency in the revenue producing activities of their businesses, the emphasis of this article is on the importance of usable and up-to-date knowledge about support activities of the business that an entrepreneur must continually acquire to remain a viable going concern. The article encourages small business owners to recognize the absolute necessity of including a viable continuing education program about these support functions in their plans for success.

The discussion presented in the article focuses on the continuing education resources available to small business owners through various profit and not-for-profit organizations. They facilitate entrepreneurs acquire the knowledge and skills they need to preserve the vitality of their businesses. Small business owners abreast of the available, and often free, educational resources are more likely to take advantage of such resources in identifying effective courses of actions when faced with an issue or an opportunity. More importantly, such business owners would tend to incorporate continuing education and training as a paramount part of their business "plan for success." 


\section{AUTHOR INFORMATION}

Rubik Atamian is an associate professor of accounting at The University of Texas - Pan American. Dr. Rubik Atamian has been with UTPA since 1986, before which, he taught at UT-Austin and Texas Tech University. He has published several peer reviewed journal articles as well as many guest columns on diverse business issues including some addressing various aspects of small business operations and management.

Neal R. VanZante is an associate professor of accounting at The University of Texas Pan American. Dr. VanZante is a licensed Certified Public Accountant in Oklahoma, Colorado, and Texas as well as a Certified Management Accountant, a Certified Financial Manager, and a Certified Fraud Examiner. He is an active member of a large number of academic and professional organizations. He has authored or coauthored a large number of articles in professional accounting journals and in other business publications.

\section{REFERENCES}

1. Atamian, A, Wagman, G. \& VanZante, N. (2009). Practical advice for individuals considering opening a small business. Journal of Business \& Economics Research (July, 2009), pp. 33-37.

2. Isidro, I. (2008). 10 rules for small business success. PowerHomeBiz.com. www.powerhomebiz.com/vol19/rules.htm. Accessed October 13, 2008.

3. Internal Revenue Service (IRS). (2009). Small business and self-employed tax center. http://www.irs.gov/businesses/small/index.html. Accessed August 9, 2009.

4. $\quad$ Rosenberg, Joyce. M. (August 7, 2008). Small business owners have many learning options. http://accounting.pro2net.com/x62821.xml. Accessed August 5, 2009.

5. $\quad$ SCORE “Counselors to America's Small Business." (2009). About SCORE. http://www.score.org/explore_score.html. Accessed August 8, 2009.

6. Small Business Administration (SBA). (2009). About SBA. http://www.sba.gov/aboutsba/index.html. Accessed August 8, 2009.

7. Small Business Development Center (SBDC). (2009). About SBDC. http://www.sba.gov/aboutsba/sbaprograms/sbdc/aboutus/index.html. Accessed August 9, 2009.

8. Schaefer, P. (2006). The seven pitfalls of business failure and how to avoid them. Business Know-How. www.businessknowhow.com/startup/business-failure.htm. Accessed October 12, 2008. 